\title{
An Inquiry into Success Factors for Post-disaster Housing Reconstruction Projects: A Case of Kerala, South India
}

\author{
Shyni Anilkumar ${ }^{1}$ Haimanti Banerji ${ }^{2}$
}

Accepted: 11 August 2020/Published online: 15 October 2020

(C) The Author(s) 2020

\begin{abstract}
The 2004 Indian Ocean Tsunami triggered significant destruction to housing and related infrastructures across various coastal districts of south India. Research shows that tsunami reconstruction projects in Kerala experienced different degrees of success and failure. On this background, this study explored factors that contributed to the successful implementation of tsunami housing projects in Kerala by (1) consolidating various critical success factors (CSFs) for post-disaster reconstruction (PDR) projects under "project management success traits" through content analysis of existing literature; (2) deriving a conceptual model that envisages project success in PDR contexts; and (3) assessing the impacts of those success traits on tsunami housing projects using confirmatory factor analysis. Necessary data were gathered through a survey of various stakeholders involved in tsunami reconstruction projects in Kerala using structured questionnaires. The research revealed that PDR project success is attributed to critical dimensions of project management such as institutional mechanisms, reconstruction strategies, project implementation, and stakeholder management. A conceptual model with the interplay of project success, success traits, as well as their CSFs identified the project management actions that must be monitored during reconstruction. Since the project management approach is widely recognized for PDR projects,
\end{abstract}

Shyni Anilkumar

shyni@nitc.ac.in

1 Department of Architecture and Planning, National Institute of Technology, Calicut, Kozhikode, Kerala 673601, India

2 Department of Architecture and Planning, Indian Institute of Technology, Kharagpur, Kharagpur, West Bengal 721302, India these success traits hold huge potential for effective organization and management of housing reconstruction projects. The study also helped to identify project management traits that need improvements for the successful implementation of post-disaster housing projects in Kerala. Thus the research findings can serve as a foundational study for formulating project management strategies appropriate to PDR projects in Kerala.

Keywords Critical success factors - Housing project management success traits $\cdot$ India $\cdot$ Post-disaster housing reconstruction

\section{Introduction}

Kerala, the southernmost state of India on its southwest coast, is vulnerable to a range of hazards such as cyclones, earthquakes, floods, landslides, and so on. The Kerala coast frequently experiences severe erosion, necessitating frequent evacuation and rehabilitation of coastal communities, especially during the monsoon. The state is vulnerable to cyclones and experiences high winds due to cyclonic storms along the Bay of Bengal. Kerala also falls under seismic zone III, making it vulnerable to earthquakes of a magnitude of 6.5 or higher. The 2004 Indian Ocean Tsunami and the flooding of 2018 and 2019 have added a new dimension to the disaster scenario of the state.

Successful reconstruction of damaged infrastructures, especially housing, is inevitable for the sustainable recovery of the disaster-affected community. However, a range of management issues arises during the implementation of large-scale housing reconstruction programs due to the contextual characteristics of the post-disaster environment (Hidayat and Egbu 2013; Ophiyandri et al. 2013; Bilau and 
Witt 2016). Failure to manage such issues of reconstruction projects by the implementing organizations results in the ineffective delivery of reconstruction programs (Ophiyandri et al. 2013) and leads to later modification or outright rejection of reconstructed housing by the users (Shaw and Ahmed 2010). The post-tsunami project environment in Kerala encountered a host of policy and strategy issues that affected the successful planning and implementation of housing reconstruction projects (CAG India 2007; Joseph 2015). Consequently, tsunami relocated communities were found to be dissatisfied with the living environment in terms of quality of housing and other infrastructures, sociocultural and economic sustainability, and more (Joseph 2015).

In light of the unique characteristics of disaster reconstruction project environments, researchers have identified numerous critical success factors (CSFs) that are likely to influence the success of reconstruction projects (Moe and Pathranarakul 2006; Steinfort and Walker 2007; Ahmed 2011; Wardak et al. 2012; Hidayat 2013; Kim and Choi 2013; Ophiyandri et al. 2013). Critical success factors are characteristics, conditions, or variables that influence project success when properly sustained, maintained, or managed (Milosevic and Pathranarakul 2005). However, it is not feasible to assess the impact of individual CSFs on the success of a project, as they pertain to various phases of the reconstruction process. There is hardly any consensus in the literature on the classification of CSFs for better interpretation of their impact on project success. Having realized the relevance of CSFs and their characteristics, researchers have advocated a project management perspective for the successful implementation of post-disaster reconstruction (PDR) projects (PMI 2005; Silva 2010; Baroudi and Rapp 2011; Ismail et al. 2014). Project management is the application of various skills, tools, and techniques that enable project staff to oversee project planning, organization, and implementation, leading to project efficiency and effectiveness.

Integrating know-how on project management into disaster recovery operations leads to higher success rates (Omimah and Emrah 2016). It has been observed that the process of procuring and governing housing are the reason for poor performance of many post-disaster housing reconstruction projects (Andrew et al. 2013; Bilau et al. 2015), and poor planning and implementation of reconstruction projects can also create further vulnerabilities in a disaster-affected community, leading to the failure of these projects (Chang et al. 2010). In India, the National Policy on Disaster Management 2009 as well as the National Disaster Management Plan 2016 have advocated a projectoriented approach for PDR. Consequently, the Kerala State Disaster Management Policy 2010 upheld project management as a key activity in the recovery phase and recommended following the best practices in the past project management experience of the state.

According to Toor and Ogunlana (2005) every project has a specific set of success factors, which may not be transferable to another project due to the differences in environmental variables as well as the nature of the project and project management organization. Because Kerala is highly susceptible to disaster-related loss (GoK 2016) the implementing agencies must be equipped to effectively plan and execute the reconstruction activities. However, there has been hardly any attempt to identify the most significant factors that decide project success in post-disaster reconstruction in Kerala. On this backdrop, the study set the following objectives:

1. Consolidate various CSFs for PDR projects under project management success traits;

2. Propose a conceptual model for project success that encapsulates project management dimensions as well as their CSFs;

3. Analyze the effects of the identified success traits on the successful delivery of housing reconstruction projects in the study context.

In the following the case study region is introduced, followed by the theoretical approach and the conceptual model for project success. The research methodology to operationalize the conceptual model attributes is described in Sect. 4. The statistical analyses and the discussion of the findings are outlined in Sect. 5. Finally we draw inferences and highlight the contributions of this study to the body of knowledge as well as the limitations of the study, and make suggestions for further research.

\section{Research Context: Reconstruction Projects in Kerala after the 2004 Tsunami}

The 2004 Indian Ocean Tsunami caused significant damage and destruction to three coastal states in India-Tamil Nadu, Andhra Pradesh, and Kerala. Figure 1 shows the regions affected by the tsunami. In Kerala, 219 villages in nine districts (out of 14) were affected (MHA India 2005). However, tsunami-related damages were severely felt in 187 villages along the coast in three southern districtsErnakulam, Alappuzha, and Kollam (Sheth et al. 2006). Housing and related infrastructures suffered the most extensive damage and loss during the tsunami. Almost 20,000 housing units in the coastal villages either were damaged or fully destroyed (MHA India 2005). Among the tsunami-impacted villages in Kerala, the largest number of casualties and damages were reported from the Alappad coastal panchayat (village council) in Kollam District. Alappad is a low-lying coastal belt approximately $16 \mathrm{~km}$ 


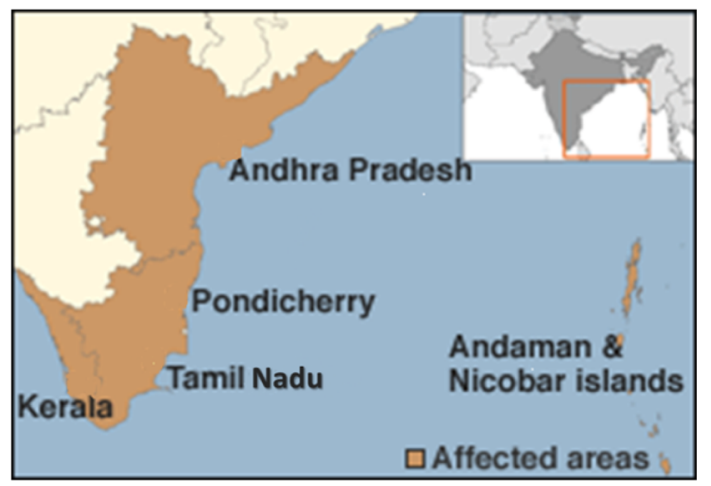

Fig. 1 Areas in India affected by the 2004 Indian Ocean Tsunami Source https://www.who.int/hac/crises/international/asia_tsunami/ ind/en/

long and 50-200 m wide with a population density of 2652 persons $/ \mathrm{km}^{2}$ versus the state average of 819 persons $/ \mathrm{km}^{2}$ when the tsunami struck (India 2005). This unprecedented calamity affected the already delicate economy of Alappad, causing havoc and hardships to the people. Over 35,000 people from Alappad village were initially accommodated in relief camps organized in 28 locations. Houses in close proximity to coastal areas were damaged beyond repair. About 2194 houses were completely destroyed and 3000 houses were seriously damaged in Alappad village (TRP 2011).

Two strategies were adopted for providing permanent housing for the tsunami-affected communities: relocating the communities within $200 \mathrm{~m}$ of the shore to new settlements inland; or rebuilding on the original land that is $200 \mathrm{~m}$ beyond the coastline. Subsequently, new houses were constructed in situ or communities were relocated to new settlements inland following owner-driven as well as donor-driven approaches. The state government of Kerala functioned as the lead agency for managing the long-term recovery programs post tsunami. The district administration was entrusted with the planning and implementation of reconstruction activities in each district. The district administration acquired suitable land for relocation of tsunami-affected communities to safer areas. They identified the beneficiaries for permanent houses at various locations and reconstruction was carried out by nongovernmental organizations (NGOs). A total of 22 NGOs, national as well as international, were involved in the rebuilding process.

More than $50 \%$ of the disaster-affected families possessed land within $20 \mathrm{~m}$ of the coastline pre-tsunami. Subsequently, new houses were constructed in the relocated settlements in three panchayats inland, 3-5 km away from the original settlements (TRP 2011). Over 5000 houses were constructed in 60 new settlements following a donor-driven approach. Figure 2 shows the location of Alappad village and the neighboring panchayats to which tsunami-displaced communities were relocated. A typical design was followed for the dwelling units in various settlements, maintaining equity in housing facilities. Each house had a plinth area of $40 \mathrm{~m}^{2}$ with two bedrooms, a small hall, an open verandah, a kitchen, one toilet cum bathroom, and an external staircase. After the completion of the project within the stipulated period (2006-2010), the NGOs handed over the housing units to the government. There was no involvement of the affected communities or their representatives in the planning and design of new
Fig. 2 Alappad Village and neighboring panchayats (village councils) in the state of Kerala, India

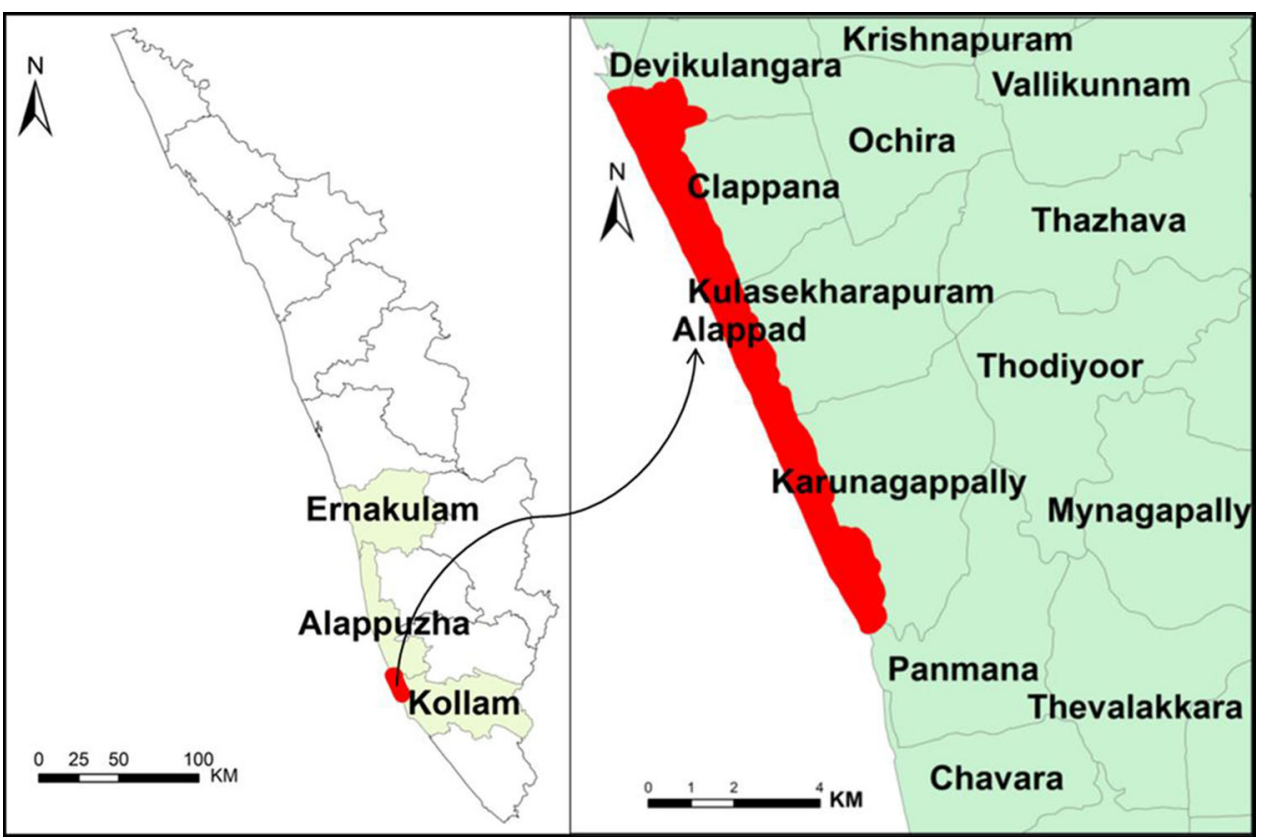


settlements for relocation. The housing units were distributed to the eligible beneficiaries through random allotment without seeking the community preferences on the location of new neighborhood as well as housing unit.

Since there was no precedence for a large-scale disaster like the 2004 tsunami in Kerala, the state was unprepared to tackle the complex reconstruction activities. Consequently, post-tsunami rehabilitation programs-funded and implemented by national and international agencies following different governance structures and implementation mechanisms (Joseph 2015) - encountered numerous challenges. Limited human resources, lack of experience and management skills of implementing agencies, as well as delays in establishing institutional support, were the major challenges that were initially faced by the disaster management agencies operating at the state level (CAG India 2007). Assessments of damage and fund requirements were conducted arbitrarily and in many cases inflated. Reconstruction projects were planned and implemented by the existing bureaucratic administrative system, with limited participation of local self-government departments (bodies that look after the administration of an area or a small community such as a village, town, or city) and the affected communities (Joseph 2015). All these issues resulted in a lack of transparency and accountability, corruption, escalation of prices, delays in purchase of land, and subsequent delays in providing houses (CAG India 2007).

Various reconstruction projects experienced different degrees of success and failure and the resettled community was dissatisfied with the new living environment in terms of quality of housing and other infrastructures, and sociocultural and economic sustainability (Joseph 2015). Having established the reconstruction project scenarios, the donordriven housing projects for the tsunami-displaced community of Alappad Panchayat, Kollam District were considered an ideal case study for identifying the factors of project success in post-disaster situations in Kerala.

\section{Theoretical Approach}

The primary concern of the research was to consolidate the critical success factors under project management success traits and analyze their influence on the success of posttsunami housing projects in Kerala. From a critical review of relevant literature on CSFs for reconstruction projects, the study hypothesized the association of CSFs with specific success traits that characterize primary dimensions of project management. This is followed by proposing a conceptual model that encapsulates these critical success factors and project management dimensions.

\subsection{Critical Success Factors for Post-disaster Reconstruction Projects: An Overview}

Research indicated numerous CSFs either specific to certain disaster situations or to different types of reconstruction activity. Based on the case study of the 2001 Gujarat earthquake, for example, Shaw et al. (2002) proposed CSFs as a guideline for international organizations involved in reconstruction projects. Catholic Relief Services (CRS), a humanitarian organization, highlighted success factors drawing on case studies globally (CRS 2011). From the studies on projects aided by external agencies, Steinfort and Walker (2007) identified 10 key success factors related to the project management processes of aid projects. While Ahmed (2011) explored CSFs for post-disaster housing reconstruction projects in developing countries, Wardak et al. (2012) examined case studies of failed reconstruction projects around the world and listed factors of project failure. Ophiyandri et al. (2013) identified 12 CSFs for community-based housing reconstruction projects in Indonesia. Other relevant research that identified CSFs include: Moe and Pathranarakul (2006) identified CSFs for public reconstruction projects; Kim and Choi (2013) investigated CSFs for rebuilding projects for flood-affected communities in Korea; Hidayat (2013) highlighted CSFs for post-tsunami reconstruction projects in Indonesia; Choudhary and Mehmood (2013) consolidated CSFs for reconstruction after the 2005 earthquake in northern Pakistan; Jordan and Javernick-Will (2014) researched on CSFs for housing reconstruction projects in Tamil Nadu after the 2004 tsunami; Liu et al. (2016) looked into CSFs for strengthening infrastructure recovery management, and so on. Because CSFs are extensive in scope, the most cited CSFs for PDR projects in general, as well as specific to housing reconstruction projects in various contexts, are summarized in Table 1.

These determinants of success or failures of reconstruction projects were assembled from a literature review. The following section attempts to consolidate these factors under major success traits.

\subsection{Classification of Critical Success Factors under Project Management Success Traits}

The adaptability of knowledge in the area of project management for PDR projects has been established in various studies. The International Project Management Institute (PMI), for example, established a project management methodology specific to PDR projects (PMI 2005). It is also established that the managerial and organizational aspects for planning and implementation of nondisaster projects could assist in disaster situations (PMI 2005; Moe and Pathranarakul 2006). Several studies 
Table 1 Critical success factors (CSFs) for post-disaster reconstruction (PDR) projects

CSFs References

Participation and empowerment, flexibility and time frame, teamwork, identity and ownership, trust, evaluation, transferability

Effective institutional arrangement, coordination and collaboration, supportive laws and regulations, effective information management system, competencies of managers and team members, effective consultation with key stakeholders and target beneficiaries, effective communication mechanism, stakeholders' commitments, effective logistics management, sufficient mobilization and disbursement of resources

Sensible budget, political goodwill, community cooperation, consultation and participation, understanding of local conditions

Climate-responsive housing design, cultural appropriateness, owner-driven approach, teamwork, skills and experience of the project team, contractor capacity and reliability, technical and management resources

Coordination of organizations, availability of resources, human resources

Community empowerment, community participation, communication and information dissemination, community culture and beliefs, support from local government

Good governance, multilateral coordination, accountability, organized community participation, reasonable resource allocation, appropriate land-use planning and policies, appropriate building materials and construction methods, pre-disaster planning, integrated risk management, enhanced local knowledge and capacity, acceptable partnership of local, national, and international agencies

Transparency and accountability, appropriate reconstruction strategy, community-based method, gathering trust from the community, facilitator capacity, good coordination and communication, sufficient funding availability, implementer capacity, significant level of community participation/control, successful beneficiary identification, government support

Effective project monitoring and control, Adequate funding, Competent project management, Effective project planning, Sufficient resources

Clear project plan, improvement in design management, enhancement of coordination at the planning stage, design and construction interface, rapid evaluation of contractor's qualification

Project manager's competence, senior management support, project management skill, coordination among project participants, clarity of goals, project planning, training of human resources on disaster resistance reconstruction techniques, user participation, monitoring and feedback by project participants, stakeholder management, contractor's competence, adequate financial resources, quality management, land availability, construction materials, political support, better governance, synergy between governmental and nongovernmental agencies

Recovery agency's embeddedness in communities, community participation, agency oversight during reconstruction

Shaw et al. (2002)

Moe and Pathranarakul (2006)

Ahmed (2011)

CRS (2011)

Hidayat and Egbu

(2011, 2013)

Sadiqi et al. (2013)

Yi and Yang (2013)

Ophiyandri et al. (2013)

Hidayat (2013)

Kim and Choi (2013)

Choudhary and Mehmood (2013)

Establishment of a recovery vehicle, formulation of flexible funding plan, community engagement, selection of a Liu et al. (2016) rebuild driver, project prioritization methodology, standardization of data management mechanism

indicated that adopting structured project management approaches would result in improved project outcome for inherently complex PDR projects (Silva 2010; Baroudi and Rapp 2011; Ismail et al. 2014). Prieto and Whitaker (2011) stated that post-disaster project management activities are largely modified from non-disaster activities. Project management best practices and the knowledge area of normal constructions (non-disaster) could assist in disaster situations as well (Moe and Pathranarakul 2006; Bilau et al. 2015).

However, assessing the impact of individual CSFs on the success of a project may not be feasible as they vary in scope and purpose. A universal classification of CSFs into success traits for PDR projects is sparsely attempted in the existing literature. Nevertheless, in the case of non-disaster construction projects CSFs have been consolidated under unique success traits, characterizing project management dimensions as major factors of project success (Tabish and Jha 2012; Ngacho and Das 2016). Table 2 consolidates the classification of CSFs and their description for non-disaster construction projects.

However, these model classifications of CSFs cannot be adapted directly to PDR projects, as the project environment differs from normal construction contexts. With this backdrop, drawing on the grouping of success factors for normal construction project scenarios, we classified frequently cited CSFs for post-disaster projects under four primary dimensions of project management-institutional mechanism, reconstruction strategy, project implementation, and stakeholder management, which are key project management success traits. An outline of the project 
Table 2 Critical success factors for non-disaster projects and their description

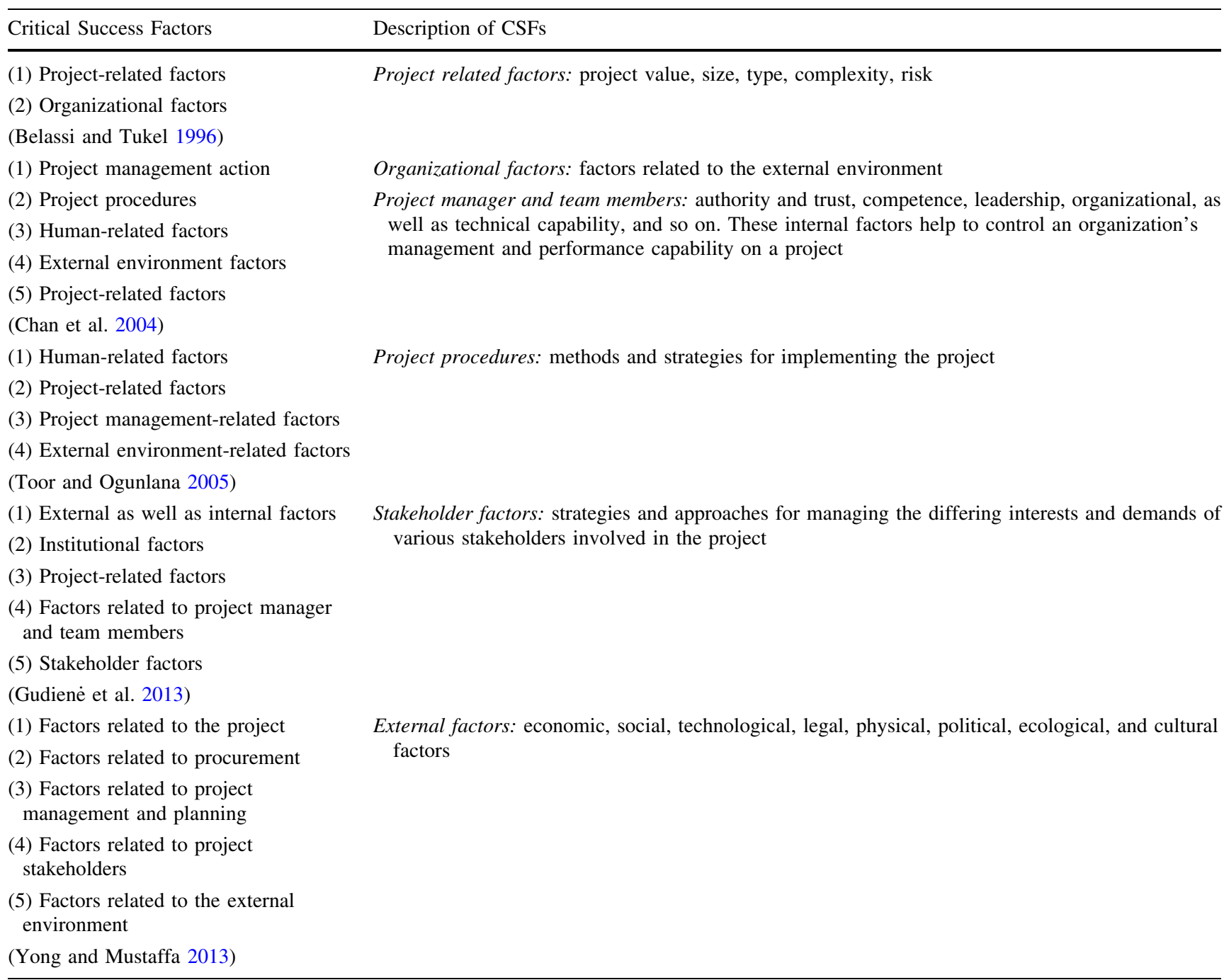

management success traits, the CSFs, as well as their relationship is presented below.

Institutional Mechanism: The success or failure of reconstruction projects largely depends on the ability to tackle the governance issues that arise in post-disaster situations (Harvey 2009). An appropriate institutional mechanism is the best way towards tackling governance issues as emphasized by Joseph (2015). Institutional arrangements for disaster management commonly include the establishment of a single entity at each level of government (Mattingly 2002). In India overall, as well as in Kerala, reconstruction activities were carried out by formulating stand-alone Extraordinary Mechanisms (Thiruppugazh 2014). Several factors determine the nature and mandate of the institutional mechanism. According to Haas et al. (1977) quality of leadership, planning, and organization for reconstruction characterizes good institutional arrangement. Rubin et al. (1985) argued that leadership, ability to act, knowledge of available resources, and capacity of local officials determine success or failure of a reconstruction program. Political will, availability of resources, requirements of international financial institutions, and the nature of bureaucratic and political leadership (Thiruppugazh 2014) are also important for an efficient institutional mechanism after disasters. Finally, government support is a prime factor for facilitating inclusive planning processes in post-disaster situations.

Reconstruction Strategy: An appropriate reconstruction approach provides better opportunities to rebuild damaged structures and enhance disaster resilience (Pribadi et al. 2014). Sustainable recovery objectives, such as social equality and hazard mitigation can be achieved when the strategies meet local needs, and local capacity is given due consideration by implementing agencies. The rebuilding 
strategy must also include risk management, monitoring, and evaluation of the capabilities of the organizations as well as the mechanism to coordinate their involvement (Jha and Duyne 2010). Hayles (2010) suggested that reconstruction strategies must find a balance between affordability, technical feasibility, and quality of life.

Project Implementation: Implementation strategies in disaster contexts suggest how reconstruction should be executed to deliver efficient project outcome. Mannakkara et al. (2014) pointed out that despite having risk reduction and community recovery strategies in place, successful achievement of recovery objectives requires effective and efficient implementation. They emphasized that the enforcement of building regulations, transparent need assessment, effective logistics and resources, adequate technical support, and a mechanism for quality control and timely feedback are essential for effective project implementation. Bilau et al. (2015) identified factors such as monitoring and control, logistics and supply chain, human resources, workmanship, quality, and so on as affecting project implementation.

Stakeholder Management: Reconstruction demands the participation of various stakeholders such as the community, local government, the private sector, NGOs, international funding agencies, and so on. Stakeholder participation is found to be critical for the success of postdisaster reconstruction projects (Hayles 2010; Chang et al. 2011; Chandrasekhar 2012; Jigyasu 2013). Mannakkara and Wilkinson (2013) noted that a clear understanding of stakeholders' roles and their effective coordination and participation in the reconstruction process leads to project efficiency. However, ensuring cooperation and collaboration among various stakeholders is a major issue that impedes governance after a disaster (Asgary et al. 2006). Identifying the potential stakeholders and analyzing their needs, good communications (Yang et al. 2009), and stakeholder empowerment (Davidson et al. 2007) are also critical to mobilizing stakeholder creativity, resources, and capacities.

\subsection{Conceptual Model}

The critical success factors included in each of the four principal groups are likely to interact, inform, and influence each other in the process of achieving a successful project outcome. In order to analyze the influence of these success traits on project success, we developed a conceptual model (Fig. 3). This model presents the project management success traits as first-order constructs composed of CSFs, whereas reconstruction project success is conceptualized as a higher-order construct influenced by the first-order success traits. Such a multilevel analysis of multiple factors would maximize the interpretability of the model dimensions (Hair et al. 2010). Critical success factors from existing literature that are identical in nature were combined and renamed logically, and only frequently cited factors were retained in the conceptual model because the inclusion of irrelevant variables can result in poor model fit in subsequent quantitative analyses (Whitehead 1998).

The conceptual model consolidated the project management success traits and the potential project management actions necessary for the successful implementation of reconstruction projects. This model provides a checklist of project management actions that require due consideration in a post-disaster project environment. Moreover, the existing guidelines for post-disaster reconstruction by Sphere Standards, ${ }^{1}$ the National Disaster Management Agency (NDMA), ${ }^{2}$ and the provisions in the National Building Code $^{3}$ are overly technical with a product-oriented approach towards shelter reconstruction. Rather this model attempts to comprehend the "management processes," and emphasizes a process-oriented approach for reconstruction.

\section{Research Methodology}

This research hypothesized that the success of PDR projects is influenced by the critical success factors of four major project management success traits-institutional mechanism, reconstruction strategy, project implementation, and stakeholder management. The identification and consolidation of CSFs were done through literature analysis. A primary survey using a structured questionnaire was employed to draw on the extent to which the various CSFs had been practiced during reconstruction of tsunami displaced community in Alappad Panchayat. Statistical analysis using SPSS (Statistical Software for Social Science) as well as AMOS (Analysis of Moment of Structures) were deployed to validate the project management success traits and to analyze their influence on project success. This approach of integrating qualitative and quantitative techniques was also found in earlier research that investigated CSFs in disaster-related projects (Choudhary and Mehmood 2013; Ophiyandri et al. 2013; Enshassi et al. 2017).

\subsection{Stakeholder Population of the Study}

This study was framed to understand the project-oriented success factors that were practiced during the post-tsunami housing reconstruction projects in Kerala and targeted various stakeholders involved in a major way in the

\footnotetext{
${ }_{1}$ https://www.spherestandards.org.

2 https://ndma.gov.in/.

${ }^{3}$ https://bis.gov.in.
} 


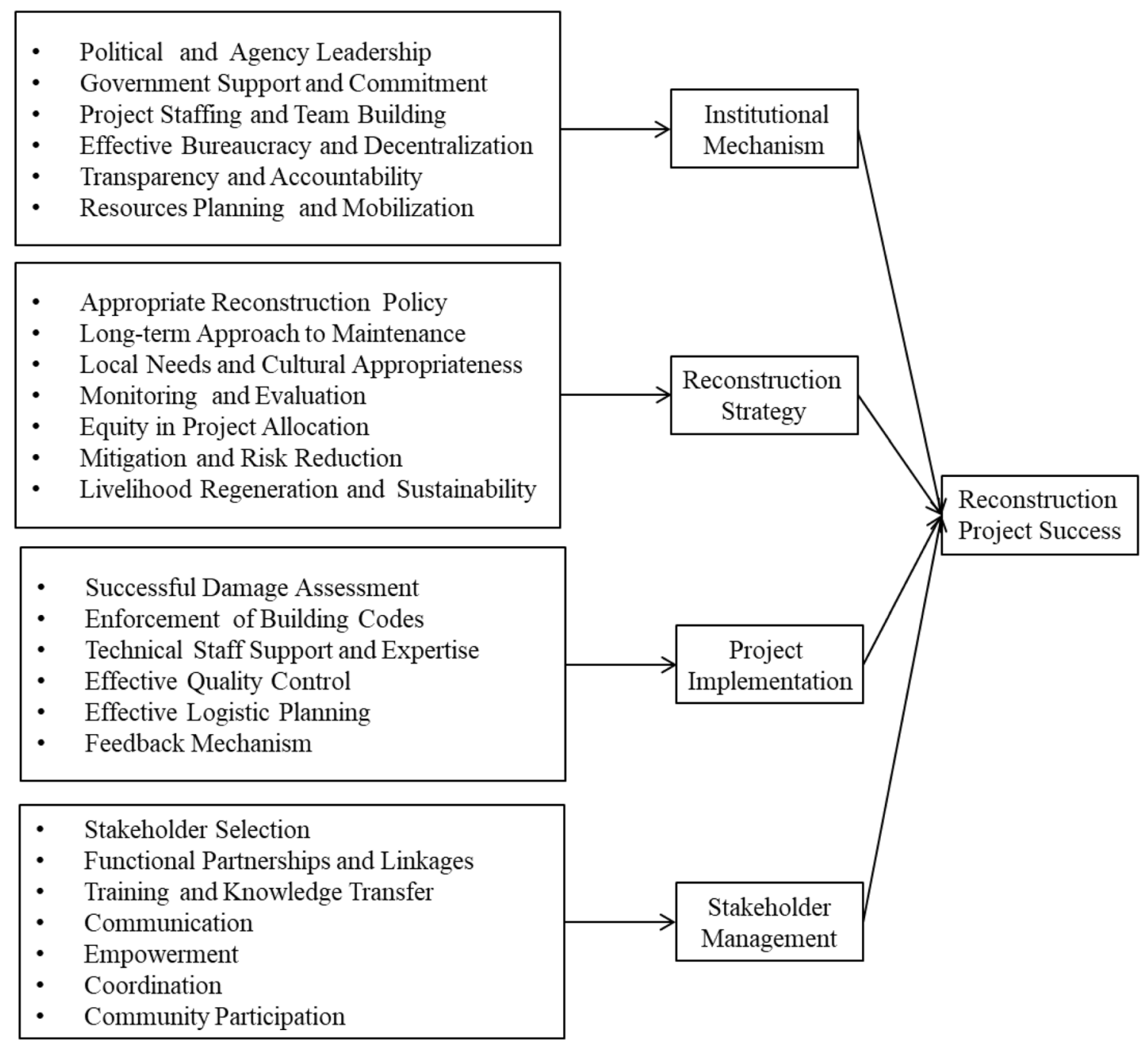

Fig. 3 Conceptual framework for reconstruction project success

planning and implementation of housing reconstruction projects. However, as representatives of the project users, community leaders from various resettlements were given due consideration during the sample selection. Given the difficulties in contacting stakeholders involved in specific completed projects, stakeholders generally involved in the relocation of Alappad Panchayat community were targeted for the survey. This approach has been followed for research in construction project management (Chan et al. 2004). The targeted population included: state and local government officials involved in the planning and policy making for disaster reconstruction; program implementing officers at the various levels of government such as officers of district administrations, taluk offices (an administrative division within a city or town that serves as its administrative center, with possible additional towns, and usually a number of villages), village offices; and architects, engineers, and contractors. Officers from various line departments like state housing boards, town planning departments, public works departments, and water authorities, who were in the mainstream of implementing various infrastructure services, elected representatives, leaders of local civic networks, representatives of communities, religious organizations and active women groups, community leaders from various relocated settlements, and so on were also surveyed.

\subsection{Data Collection Method}

Since there are no official records of stakeholders involved in post-tsunami reconstruction projects, the size of the population was unknown. Hence the survey employed a snowball sampling technique where initial respondents helped to identify other potential respondents. The primary survey was conducted during an extended period from December 2015 to October 2016. The data were collected 
with questionnaires implemented face-to-face. The research gathered survey responses on the critical success factors summarized from the literature (26 items, Fig. 3). A five-point Likert scale with anchors-1 $=$ Not at all, $2=$ To a little extent, $3=$ Not sure, $4=$ To a great extent, $5=$ To a very great extent-was used, to understand the extent to which the project management measures had been practiced or emphasized during housing reconstruction. The questionnaire also gathered demographic information from the respondents, the type of reconstruction projects they were involved in, and their experience associated with construction projects in general and reconstruction projects in particular. Responses from 165 questionnaires were obtained through the survey. This sample size satisfies the minimum ratio of items to respondents (ratio of 1:5) for carrying out factor analysis (Hair et al. 2010). The sample consisted of $52(31 \%)$ government level program officers, 77 (47\%) project implementing officers, and $36(22 \%)$ community leaders from various relocated settlements. The sample fairly represented the different stakeholders, ensuring consistency and reliability of responses.

\subsection{Data Analysis Method}

The study utilized confirmatory factor analysis (CFA) for validating the conceptual model proposed in the study. Confirmatory factor analysis is a method to assess how well the observed variables (CSFs) reflect latent variables (success traits) in the hypothesized model. Initially, the measurement items were individually checked for consistency and reliability on the basis of Cronbach's alpha, item-total correlation, as well as factor loading from principal component analysis using SPSS software (version 23.0). Cronbach's alpha indicates how closely related the set of measurement items are as a group. Item-total statistics provide an assessment of the extent to which measurement items on a scale are assessing the same content. Factor loadings of measurement items represent the relationship of each variable to the underlying latent factor.

After the primary analysis for consistency and reliability of the data, the measurement items were purified based on the acceptable fit statistics. Then, CFA was employed for the reliable measurement items under four major latent constructs using AMOS software (version 23.0). In the data analysis, the relationship of the model variables-including the higher-order construct, that is project success-was estimated simultaneously. Finally, the model fitness was assessed based on the acceptable cutoff values for the following goodness of fit indices: Chi square degrees of freedom $\left(\chi^{2}=\mathrm{CMIN} / \mathrm{df}\right)<3$, goodness of fit index $(\mathrm{GFI})$, comparative fit index (CFI), Tucker-Lewis index
$(\mathrm{TLI})>0.9$, and the root mean square error of approximation (RMSEA) < 0.08 proposed by Hair et al. (2010).

\section{Analysis and Findings}

The following subsections present the process of model validation, using confirmatory factor analysis (CFA). The relationship of the model variables is also established by assessing relevant statistics of CFA.

\subsection{Confirmatory Factor Analysis}

The study conceptualized the project management success traits as first-order latent constructs influenced by the measurement items (CSFs), which in turn influence the second-order construct, overall project success. In this step of data analysis, the relationship of the model variables was estimated simultaneously. Initially, the reliability and validity of the measurement items (CSFs) were tested and the results are presented in Table 3 .

The results of the validity analysis are described below. Initially, the agreement on responses by the three groups of stakeholders-government level program officers, project implementing officers, and community leaders from various relocated settlements-was analyzed using intra-class correlation coefficient (ICC). Intra-class correlation coefficient reflects the degree of correlation as well as the agreement on responses from different groups. The ICC value 0.833 given in Table 3 indicates excellent homogeneity of responses (excellent if ICC value 0.75 and above; Fleiss et al. 2013). Cronbach's $\alpha$ value ranged from 0.79 to 0.91 , indicating the internal consistency of responses on CSFs (acceptable minimum $\alpha$ is 0.6; Hair et al. 2010). However, the adequacy of the survey responses for conducting CFA was confirmed using the Kaiser Mayer Olkin (KMO) index. The KMO value for the four success dimensions is above the acceptable $(0.50$; Hair et al. 2010). The results further show that all the common factors extracted accounted for a variance ranging from 50.08 to $66.98 \%$ (Table 3). Percentage variance explained indicates the association of the measurement items with the proposed success dimensions. Overall the test results in Table 3 indicate an acceptable association between the proposed project success traits and the responses reported. The item-total correlation and factor loading of three items were found to be less than the cutoff of values of 0.30 (Nunnally 1994) and 0.5 (Hair et al. 2010), respectively. Hence these three items-IM6 (Resources planning and mobilization), RS6 (Mitigation and risk reduction), and PI6 (Feedback mechanism)—were not considered for the second stage of analysis. 
Table 3 Critical success factors and their reliability measures. Source SPSS output

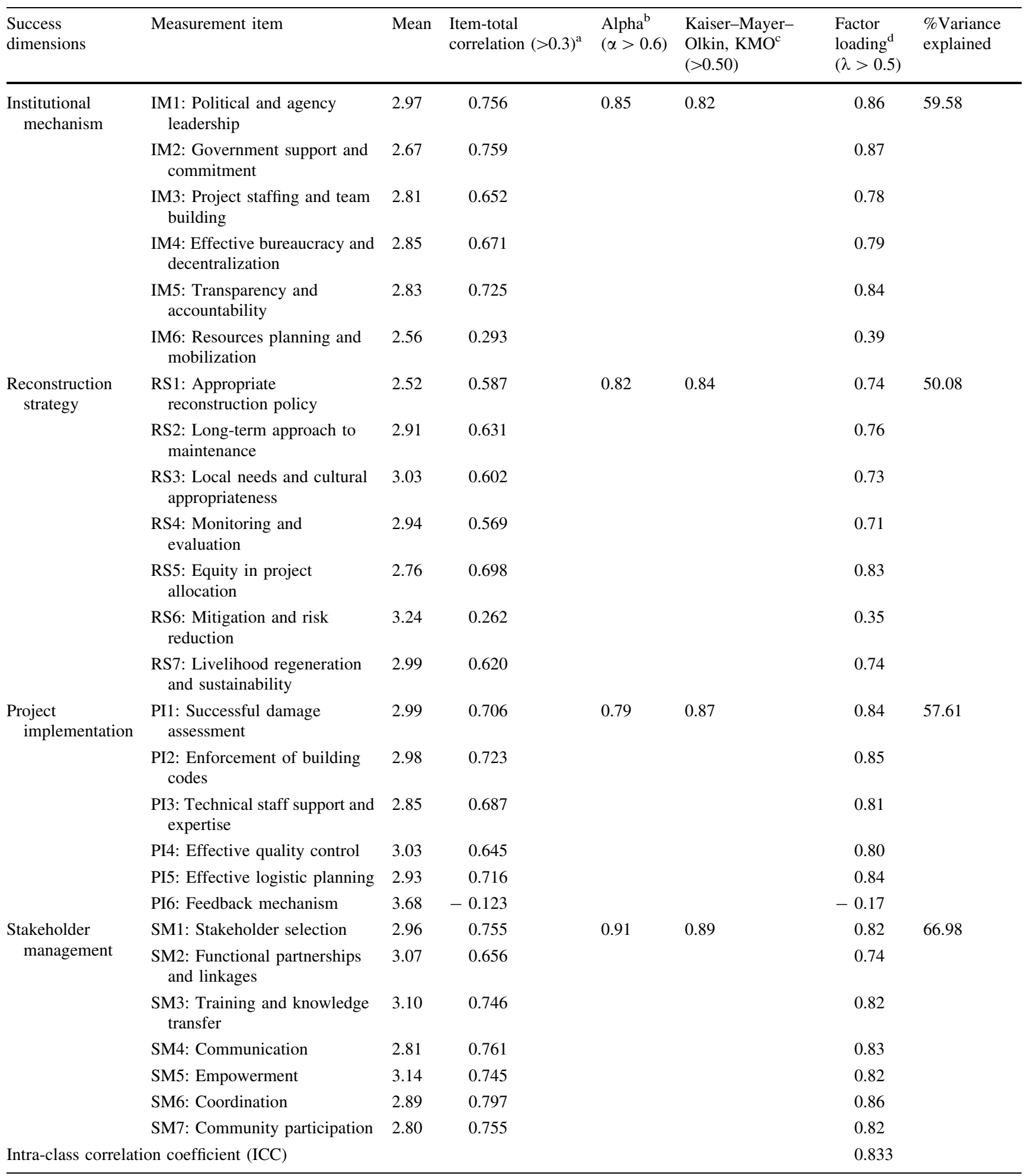

${ }^{\mathrm{a}}$ Item-total correlation must be greater than 0.30 (Nunnally 1994)

${ }^{\mathrm{b}}$ Alpha values of $60 \%$ or higher are considered acceptable (Hair et al. 2006)

${ }^{\mathrm{c}} \mathrm{KMO}$ static value above 0.5 is acceptable (Hair et al. 2006)

${ }^{\mathrm{d}}$ Factor loading greater than 0.5 is acceptable (Hair et al. 2006) 


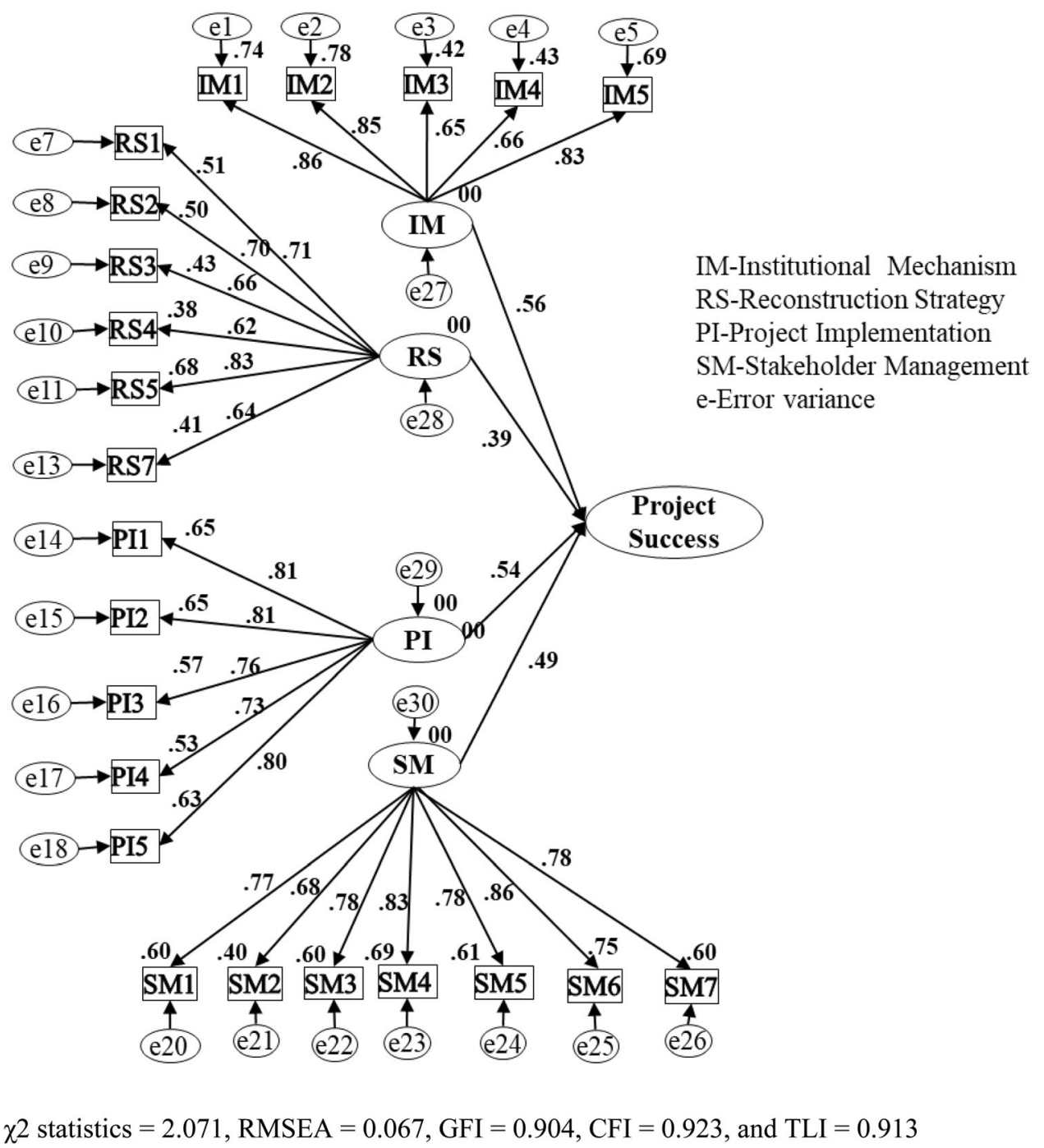

Fig. 4 Second-order project success model

After confirming the validity and reliability of the CSFs consolidated in the study, the project success model was tested using CFA. Figure 4 shows the 23 items confirmatory factor model generated from AMOS 23 statistical software. The confirmatory analysis yielded acceptable fit statistics values $\left(\chi^{2}\right.$ statistics $=2.071$, Root mean square error of approximation (RMSEA) value $=0.067$, Goodness of fit index (GFI) value $=0.904$, Comparative fit index (CFI) value $=0.923$, and Tucker-Lewis index $(\mathrm{TLI})=$ 0.913), supporting the acceptance of the model as explained in Sect. 4.3. The fit statistics indicate that project success in the case study context is governed by four firstorder success traits-institutional mechanism, reconstruction strategy, project implementation, and stakeholder management.

In order to validate the correlation between the variables of the project success model, composite reliability, as well as the convergent validity of the model dimensions, were assessed. Composite reliability measures the internal consistency of the measurement items in the model whereas convergent validity, measured using average variance extracted (AVE), indicates the extent of the correlation between the first-order latent constructs and their measurement items. The results of the validity tests are presented in Table 4.

The reliability and validity of the model dimensions were established with composite reliability greater than 0.7 and average variance greater than 0.5 (Hair et al. 2010). The analysis also showed that the CSFs associated with the first-order dimensions of the model are important, as the factor loading is above the threshold value of 0.5 (Table 4). Various reliability and validity tests on the data collected confirm that the CSFs theorized in the study are associated to project the management success traits concerned. 
Table 4 Statistical correlation between the model variables. Source AMOS output

\begin{tabular}{|c|c|c|c|c|}
\hline Measurement items & $\begin{array}{l}\text { Institutional } \\
\text { mechanism }\end{array}$ & $\begin{array}{l}\text { Reconstruction } \\
\text { strategy }\end{array}$ & $\begin{array}{l}\text { Project } \\
\text { implementation }\end{array}$ & $\begin{array}{l}\text { Stakeholder } \\
\text { management }\end{array}$ \\
\hline IM1: Political and agency leadership & 0.86 & & & \\
\hline IM2: Government support and commitment & 0.88 & & & \\
\hline IM3: Project staffing and team building & 0.65 & & & \\
\hline $\begin{array}{l}\text { IM4: Effective bureaucracy and } \\
\text { decentralization }\end{array}$ & 0.66 & & & \\
\hline IM5: Transparency and accountability & 0.83 & & & \\
\hline RS1: Appropriate reconstruction policy & & 0.71 & & \\
\hline$R S 2$ : Long-term approach to maintenance & & 0.70 & & \\
\hline $\begin{array}{l}\text { RS3: Local needs and cultural } \\
\text { appropriateness }\end{array}$ & & 0.66 & & \\
\hline RS4: Monitoring and evaluation & & 0.62 & & \\
\hline$R S 5$ : Equity in project allocation & & 0.83 & & \\
\hline $\begin{array}{l}\text { RS7: Livelihood regeneration and } \\
\text { sustainability }\end{array}$ & & 0.64 & & \\
\hline PI1: Successful damage assessment & & & 0.81 & \\
\hline PI2: Enforcement of building codes & & & 0.81 & \\
\hline PI3: Technical staff support and expertise & & & 0.76 & \\
\hline PI4: Effective quality control & & & 0.73 & \\
\hline PI5: Effective logistic planning & & & 0.80 & \\
\hline SM1: Stakeholder selection & & & & 0.77 \\
\hline SM2: Functional partnerships and linkages & & & & 0.68 \\
\hline SM3: Training and knowledge transfer & & & & 0.78 \\
\hline SM4: Communication & & & & 0.83 \\
\hline SM5: Empowerment & & & & 0.78 \\
\hline SM6: Coordination & & & & 0.86 \\
\hline SM7: Community participation & & & & 0.78 \\
\hline Average variance extracted & 0.62 & 0.58 & 0.61 & 0.60 \\
\hline Composite reliability & 0.89 & 0.85 & 0.89 & 0.92 \\
\hline
\end{tabular}

Finally, to identify the impact of these success traits on the project success a regression model was defined from confirmatory factor model statistics. The overall project success is defined in terms of the "path coefficients $(\beta)$ " between the first-order success traits and second-order project success as shown in Eq. (1).

$$
\begin{aligned}
\text { Project Success }= & 0.56 \text { Institutional mechanism } \\
& +0.54 \text { Project implementation } \\
& +0.49 \text { Stakeholder management } \\
& +0.39 \text { Reconstruction strategy }
\end{aligned}
$$

In the regression model, the path coefficients are standardized regression coefficients indicating the relative degree of influence of the first-order constructs on the higher-order latent factor. The larger the coefficient value, the more influential the variable would be towards project success.

\subsection{Discussion}

The first objective of the study was to consolidate the CSFs under project management success dimensions appropriately. The acceptable fit statistics from CFA confirmed that various CSFs for housing reconstruction projects are associated to four strategic dimensions of project management-institutional mechanism, project implementation, stakeholder management, and reconstruction strategy. The empirical findings, as well as the subsequent analysis, further helped to explore the extent to which these success traits were emphasized during the post-tsunami context in Kerala. The regression model shown in Eq. (1) reflects the degree of influence of these project management dimensions on reconstruction project success. The small values of the regression coefficients of the success traits, (ranging from 0.39 to 0.56 ) present sufficient indications on various issues that collectively influenced planning and implementation of housing projects after the tsunami in Kerala. 
Equation (1) indicates that "institutional mechanism" emerged to be the most influential success trait during housing reconstruction efforts in Kerala, albeit a moderate impact as indicated by the path coefficient. Thiruppugazh (2014) emphasized that an efficient institutional system would help to speed up the construction process through a single-window approach by facilitating collective decision making. The moderate impact of the institutional mechanism on project success indicates the deficiencies of the disaster management department that was formed after the 2004 tsunami as an Extraordinary Mechanism to oversee the reconstruction activities in Kerala. This, in turn, resulted in problems, such as delays in establishing institutional support, lack of transparency and accountability, corruption (CAG India 2007), as well as improper project staffing, team building, and ineffective bureaucracy (Joseph 2015).

The normal pace of project implementation is insufficient to address the urgent needs of the disaster-affected communities. Establishing techniques and methods that enhance a rapid project implementation process is critical during post-disaster reconstruction (Choudhary and Mehmood 2013). However, project implementation was not given adequate attention during post-tsunami reconstruction in Kerala, as evident from the path coefficient value 0.54 . This is mainly attributed to factors such as arbitrary damage assessment, which leads to inflated funding requirements, and lack of experience and management skills among local implementing agencies (CAG India 2007). The project environment also experienced serious lapses in monitoring and controlling disaster-related activities (CAG India 2007), which might have challenged effective project implementation.

Even though stakeholder involvement is critical in postdisaster project success (Hayles 2010; Chang et al. 2011; Chandrasekhar 2012; Jigyasu 2013), it was inadequate during the reconstruction project cycle in Kerala. Joseph (2015) revealed that a top-down approach was largely followed for identification, selection, and execution and monitoring of housing reconstruction projects. Moreover, there was no community participation in reconstruction planning and implementation activities (CAG India 2007). The various reconstruction programs were conceived and implemented through the hierarchical bureaucratic system of governance (Joseph 2015). Similarly, in spite of the need for an appropriate reconstruction strategy for the effective implementation of the reconstruction programs (Sofyan 2010), reconstruction strategy turned to be least influential (0.37) towards project success in Kerala. This is mainly attributed to ad hoc decision making on the reconstruction process in the absence of an appropriate reconstruction strategy (Joseph 2015). Housing development in the absence of an appropriate housing reconstruction strategy resulted in community isolation and disintegration of the communities displaced from their original habitat by the tsunami (Joseph 2015). Various training programs offered post-tsunami were inadequate for the sustained livelihood of the community.

The results of this empirical study corroborated recent findings on factors for the performance of the post-tsunami resettlement projects in Kerala. The study confirmed that project success is attributed to various project management success factors during the reconstruction phase. Though the Kerala Disaster Management Policy advocated a projectoriented approach for reconstruction, the disaster management plan 2016 lacks any strategies to disseminate the same to the potential stakeholders. This study also gives sufficient indications of the deficiencies of the disaster management systems and policy in Kerala in meeting the exigencies of post-disaster reconstruction management. Hence, this could provide a foundational research to strengthen project management best practices and knowledge areas and streamline them into post-disaster reconstruction activities in Kerala.

\section{Conclusion}

This study endeavored to comprehend various critical success factors for post-disaster reconstruction projects under the strategic dimensions of project management. The impact of these success traits on post-tsunami housing projects in Kerala was further investigated with the help of a confirmatory factor model. The findings indicate that the successful implementation of housing projects to a great extent can be attributed to project management success dimensions such as institutional mechanism, reconstruction strategy, project implementation, and stakeholder management. However, the study revealed that these success traits were not given due consideration during reconstruction. The findings may help prioritize project management areas that need improvements for successful housing provision in future disaster situations in Kerala.

This study could contribute to the body of knowledge on project management in a disaster context. Primarily the study consolidated the CSFs for PDR projects under unique dimensions of project management. The project management approach being widely recognized for post-disaster projects, such a classification holds huge potential for successful reconstruction of damaged infrastructure. The conceptual model developed in this study comprehends the management process and emphasizes a process-oriented approach for post-disaster shelter development.

Nevertheless, the study poses certain limitations. The study attempted to research and model success factors that 
characterize project management dimensions. However, factors related to a project (size, cost, design, functionality, among others), context (political, environmental, as well as pre- and post-disaster socioeconomic status), and so on, may also influence project success, directly or indirectly. Similarly, CSFs under different success traits may be correlated, and a combination of CSFs may influence project success. Future research can investigate how other factors interact and contribute to PDR project success.

Open Access This article is licensed under a Creative Commons Attribution 4.0 International License, which permits use, sharing, adaptation, distribution and reproduction in any medium or format, as long as you give appropriate credit to the original author(s) and the source, provide a link to the Creative Commons licence, and indicate if changes were made. The images or other third party material in this article are included in the article's Creative Commons licence, unless indicated otherwise in a credit line to the material. If material is not included in the article's Creative Commons licence and your intended use is not permitted by statutory regulation or exceeds the permitted use, you will need to obtain permission directly from the copyright holder. To view a copy of this licence, visit http://creativecommons. org/licenses/by/4.0/.

\section{References}

Ahmed, I. 2011. An overview of post-disaster permanent housing reconstruction in developing countries. International Journal of Disaster Resilience in the Built Environment 2(2): 148-164.

Andrew, S.A., S. Arlikatti, L.C. Long, and J.M. Kendra. 2013. The effect of housing assistance arrangements on household recovery: An empirical test of donor-assisted and owner-driven approaches. Journal of Housing and the Built Environment 28(1): 17-34.

Asgary, A., A. Badri, M. Rafieian, and A. Hajinejad. 2006. Lost and used post-disaster development opportunities in Bam earthquake and the role of stakeholders. In Proceedings of the 2006 International Conference and Student Competition on Postdisaster Reconstruction "Meeting Stakeholder Interests", 17-19 May 2006, Florence, Italy. http://www.grif.umontreal.ca/pages/ papersmenu2006.htm. Accessed 10 Dec 2006.

Baroudi, B., and R. Rapp. 2011. A project management approach to disaster response and recovery operations. 36th Australasian University Building Educators Association Conference. http:// epublications.bond.edu.au/cgi/viewcontent.cgi?article= 1001\&context=aubea_2011. Accessed 12 Nov 2015.

Belassi, W., and O.I. Tukel. 1996. A new framework for determining critical success/failure factors in projects. International Journal of Project Management 14(3): 141-151.

Bilau, A.A., and E. Witt. 2016. An analysis of issues for the management of post-disaster housing reconstruction. International Journal of Strategic Property Management 20(3): 265-276.

Bilau, A.A., E. Witt, and I. Lill. 2015. A framework for managing post-disaster housing reconstruction. Procedia Economics and Finance 21: 313-320.

CAG India (Comptroller and Auditor General of India). 2007. Audit report (civil), Kerala for the year 2006-07. https://cag.gov.in/hi/ content/audit-report-civil-kerala-year-2006-07. Accessed 24 Sept 2020 .
Chan, A.P.C., D. Scott, and A.P.L. Chan. 2004. Factors affecting the success of a construction project. Journal of Construction Engineering Management 130(1): 153-155.

Chandrasekhar, D. 2012. Digging deeper: Participation and nonparticipation in post-disaster community recovery. Community Development 43(5): 614-629.

Chang, Y., S. Wilkinson, R. Potangaroa, and E. Seville. 2010. Resourcing challenges for post-disaster housing reconstruction: A comparative analysis. Building Research \& Information 38(3): 247-264.

Chang, Y., S. Wilkinson, D. Brunsdon, E. Seville, and R. Potangaroa. 2011. An integrated approach: Managing resources for postdisaster reconstruction. Disasters 35(4): 739-765.

Choudhary, M.A., and K. Mehmood. 2013. Causes of success and failure in post disaster reconstruction projects-A case study of post 2005 earthquake rehabilitation and reconstruction in Northern Pakistan.Planet@Risk, May 2013.

CRS (Catholic Relief Services). 2011. How-to guide: Managing postdisaster (re)-construction projects, ed. A. Grafweg. Baltimore, MD: Catholic Relief Services.

Davidson, C.H., C. Johnson, G. Lizarralde, N. Dikmen, and A. Sliwinski, 2007. Truths and myths about community participation in post-disaster housing projects. Habitat International 31(1): $100-115$.

Enshassi, A., T. Chatat, J. von Meding, and G. Forino. 2017. Factors influencing post-disaster reconstruction project management for housing provision in the Gaza Strip, Occupied Palestinian Territories. International Journal of Disaster Risk Science 8(4): 402-414

Fleiss, J.L., B. Levin, and M.C. Paik. 2013. Statistical methods for rates and proportions. New York: John Wiley \& Sons.

GoK (Government of Kerala). 2016. Kerala Disaster Management Plan. Kerala, India: Kerala State Disaster Management Authority, Department of Revenue and Disaster Management, Government of Kerala.

Gudiené, N., A. Banaitis, N. Banaitienè, and J. Lopes. 2013. Development of a conceptual critical success factors model for construction projects: A case of Lithuania. Procedia Engineering 57: 392-397.

Haas, J.E., R.W. Kates, and M.J. Bowden. 1977. Reconstruction following a disaster. Cambridge: MIT Press.

Hair Jr, J.F., W.C. Black, B.J. Babin, R.E. Anderson, and R.L. Tatham. 2006. Multivariate data analysis, 6th edn. Upper Saddle River, NJ: Pearson-Prentice Hall.

Hair, J.F., W.C. Black, B.J. Babin, and R.E. Anderson. 2010. Multivariate data analysis, 7th edn. New York: Pearson.

Harvey, P. 2009. Towards a humanitarian government: The role of the affected state in disaster response. Humanitarian practice network. London: Overseas Development Institute.

Hayles, C.S. 2010. An examination of decision making in post disaster housing reconstruction. International Journal of Disaster Resilience in the Built Environment 1(1): 103-122.

Hidayat, B. 2013. The role of knowledge communication in the effective management of post-disaster reconstruction projects in Indonesia. Ph.D. thesis. School of the Built Environment, University of Salford, UK.

Hidayat, B., and C. Egbu. 2011. Critical success factors associated with post-disaster reconstruction projects. In Proceedings of the 27th Annual ARCOM (Association of Researchers in Construction Management) Conference, 5-7 September 2011, Bristol, UK, 889-898.

Hidayat, B., and C. Egbu. 2013. Construction quality and knowledge communication in post-disaster reconstruction projects. In Proceedings of the International Postgraduate Research Conference (IPGRC 2013), 8-10 April 2013, University of Salford, Salford, UK, 991-1002. 
India. 2005. Census of India 2001 district census handbook. New Delhi: Office of the Registrar General, India.

Ismail, D., T.A. Majid, R. Roosli, and N.A. Samah. 2014. Project management success for post-disaster reconstruction projects: International NGOs perspectives. Procedia Economics and Finance 18: 120-127.

Jha, A.K., and J.E. Duyne. 2010. Safer homes, stronger communities: A handbook for reconstructing after natural disasters. Washington, DC: World Bank Publications.

Jigyasu, R. 2013. Long-term cultural impacts of disaster decisionmaking: The case of post- earthquake reconstruction in Marathwada, India. International Journal of Architectural Research 7(3): 14-23.

Jordan, E., and A. Javernick-Will. 2014. Successes and failures of the post-tsunami housing reconstruction program in Tamil Nadu, India. In Proceedings of the American Society of Civil Engineering (ASCE) Construction Research Congress 2014, 19-21 May 2014, Atlanta, Georgia, USA, 1199-1208.

Joseph, N. 2015. Missing link between state and community: Posttsunami reconstruction and rehabilitation of Alappad Panchayat, Kerala, India. In Strategic disaster risk management in Asia, ed. H. Ha, R.L.S. Fernando, and A. Mahmood, 129-150. New Delhi: Springer India.

Kim, K.N., and J. Choi. 2013. Breaking the vicious cycle of flood disasters: Goals of project management in post-disaster rebuild projects. International Journal of Project Management 31(1): $147-160$.

Liu, M., E. Scheepbouwer, and S. Giovinazzi. 2016. Critical success factors for post-disaster infrastructure recovery: Learning from the Canterbury (NZ) earthquake recovery. Disaster Prevention and Management: An International Journal 25(5): 685-700.

Mannakkara, S., and S. Wilkinson. 2013. Build back better: Lessons from Sri Lanka's recovery from the 2004 Indian Ocean tsunami. International Journal of Architectural Research 7(3): 108-121.

Mannakkara, S., S. Wilkinson, and R. Potangaroa, 2014. Build back better-Implementation in Victorian bushfire reconstruction. Disasters 38(2): 267-290.

Mattingly, S. 2002. Policy, legal and institutional arrangements. In Proceedings of the Regional Workshop on Best Practices in Disaster Mitigation: Lessons Learned from the Asian Urban Disaster Mitigation Program and Other Initiatives, 24-26 September 2002, Bali, Indonesia, 19-36.

MHA (Ministry of Home Affairs) India. 2005. Situation reports. Ministry of Home Affairs India. NDM Division. https://www. ndmindia.nic.in/tsunami2004/sitrep31.htm. Accessed 13 Jan 2005.

Milosevic, D., and P. Pathranarakul. 2005. Standardized project management may increase development projects success. International Journal of Project Management 23(3): 181-192.

Moe, T.L., and P. Pathranarakul. 2006. An integrated approach to natural disaster management: Public project management and its critical success factors. Disaster Prevention and Management: An International Journal 15(3): 396-413.

Ngacho, C., and D. Das. 2016. Critical success factors influencing the success of constituency development fund construction projects in Kenya: A confirmatory factor analysis. International Journal of Project Organization and Management 8(2): 172-196.

Nunnally, J.C. 1994. Psychometric theory, 3rd edn. New York: McGraw-Hill.

Omimah, A., and A. Emrah. 2016. Using construction project management know-how for disaster recovery projects-A synthesis of literature. In Proceedings of the Conference: Architecture in Emergency-Re-thinking the Refugee Crisis, 17-19 November 2016, Istanbul Kültür University and Bergen School of Architecture, Istanbul, Turkey, 166-173.
Ophiyandri, T., D. Amaratunga, C. Pathirage, and K. Keraminiyage. 2013. Critical success factors for community-based post-disaster housing reconstruction projects in the pre-construction stage in Indonesia. International Journal of Disaster Resilience in the Built Environment 4(2): 236-249.

Pribadi, K.S., D. Kusumastuti, S.A.H. Sagala, and R. Wimbardana. 2014. Post-disaster housing reconstruction in Indonesia: Review and lessons from Aceh, Yogyakarta, West Java, and West Sumatera Earthquakes. In Disaster recovery: Used or misused development opportunity, ed. R. Shaw, 197-223. Tokyo: Springer Japan.

PMI (Project Management Institute). 2005. Project management methodology for post disaster reconstruction. Newtown Square, PA: Project Management Institute.

Prieto, B., and C. Whitaker. 2011. Post disaster engineering and construction program and project management. PM World Today 13(9): 1-19.

Rubin, C.B., M.D. Saperstein, and D.G. Barbee. 1985. Community recovery from a major natural disaster. Monograph no. 41. Institute of Behavioral Science, University of Colorado, Boulder, CO, USA.

Sadiqi, Z., V. Coffey, and B. Trigunarsyah. 2013. Critical factors for successful housing reconstruction projects following a major disaster. In Proceedings of the 19th Triennial CIB World Building Congress, 5-9 May 2013, Queensland University of Technology, Brisbane, QLD, Australia, 1-12.

Shaw, J., and I. Ahmed. 2010. Design and delivery of post-disaster housing resettlement programs: Case studies from Sri Lanka and India. Report 6. Melbourne: Monash Asia Institute, Monash University.

Shaw, R., M. Kobayashi, H. Kameda, M. Gupta, A. Sharma, Y.Nakagawa, and M. Banba. 2002. International cooperation in a post-disaster scenario: A case study from Gujarat, India. Journal of Natural Disaster Science 24(2): 73-82.

Sheth, A., S. Sanyal, A. Jaiswal, and P. Gandhi. 2006. Effects of the December 2004 Indian Ocean Tsunami on the Indian mainland. Earthquake Spectra 22(S3): S435-S473.

Silva, J.D. 2010. Lessons from Aceh: Key considerations in postdisaster reconstruction. Warwickshire, UK: ARUP and Disasters Emergency Committee.

Sofyan, M.A. 2010. The strategic planning of post disaster reconstruction: A case study of Banda Aceh's Reconstruction. Ph.D. thesis. School of Geography, Planning and Environmental Management, University of Queensland.

Steinfort, P., and D.Walker. 2007. Critical success factors in project management globally and how they may be applied to aid projects. In Proceedings of the PMOZ Achieving Excellence4th Annual Project Management Australia Conference, 28-31 August 2007, Brisbane, Australia, 28-31.

Thiruppugazh, V. 2014. Post-disaster reconstruction and institutional mechanisms for risk reduction: A comparative study of three disasters in India. In Disaster recovery: Used or misused development opportunity, ed. R. Shaw, 17-39. Kyoto: Springer Japan.

Tabish, S.Z.S., and K.N. Jha. 2012. Success traits for a construction project. Journal of Construction Engineering and Management 138(10): 1131-1138.

Toor, S.U.R., and O.S. Ogunlana. 2005. What is critical for success; investigating the critical success factors and key performance indicators for mega construction projects. In Proceedings of the Singapore Project Management Institute Annual Symposium, 12 October 2005, Singapore.

TRP (Tsunami Rehabilitation Program) Kerala. 2011. Tsunami rehabilitation program report. Karunagappally Taluk, Kollam District, Kerala (in Malayalam). 
Wardak, Z.S., V. Coffey, and B. Trigunarsyah. 2012. Rebuilding housing after a disaster: Factors for failure. In Proceedings the 8th Annual International Conference of the International Institute for Infrastructure, Renewal, and Reconstruction (IIIRR), 24-26 August 2012, Kumamoto University, Kumamoto, Japan, 292-300.

Whitehead, J. 1998. An introduction to logistic regression. http:// www.personal.ecu.edu/whiteheadj. Accessed 20 Dec 2007.

Yang, J., Q. Shen, and M. Ho. 2009. An overview of previous studies in stakeholder management and its implications for the construction industry. Journal of Facilities Management 7(2): 159.
Yi, H., and J. Yang. 2013. Critical factors for sustainable reconstruction of post natural disasters. In Proceedings of the 2013 International Conference on Frontiers of Environment, Energy and Bioscience (ICFEEB 2013), 24-25 October 2013, Beijing, China, ed. D. Zheng, 824-829. DEStech Publications.

Yong, Y.C., and N.E. Mustaffa. 2013. Critical success factors for Malaysian construction projects: An empirical assessment. Construction Management and Economics 31(9): 959-978. 